\title{
Solderjet bumping packaging technique optimization for the miniaturization of laser devices
}

\author{
P. Ribes-Pleguezuelo ${ }^{1,2^{*}}$ (D) B. Septriani ${ }^{1,2}$, S. Zhang ${ }^{2}$, E. Beckert ${ }^{1}$, R. Eberhardt ${ }^{1}$, F. Wyrowski $^{2}$ and A. Tünnermann ${ }^{1,2}$
}

\begin{abstract}
Background: Low-stress soldering techniques can guarantee a minimized input of thermal energy allowing for the design and later assembly of more robust and miniaturized optical devices. However, in order to build miniaturized optical devices, these small-induced stresses produced by soldering techniques have to be investigated to guarantee that the stress-induced birefringence effects do not alter the device optical properties and requirements.

Methods: An analytical method that relates the stress-induced birefringence of laser components with their corresponding lasing capabilities has been compared to the real induced-stress results created in components packaged using solderjet technology. The main goal was to optimize the optical component packaging by using this low induced-stress soldering technique. The optimization was carried out by assessing components miniaturization while still assuring high robustness of the bond strength without creating a beam depolarization ratio of more than $1 \%$.

Results: The outcome of the study showed the possibility of assembling laser optical components down to sizes of around $300 \mu \mathrm{m}$, creating a bond strength of $5 \mathrm{~N}$ and higher, and a depolarization ratio much lower than the proposed target of $1 \%$.

Conclusions: Our results in terms of induced stress agreed with the finite element method result, which would imply correct post-processing laser simulations. This suggested that the solderjet bumping technique could robustly join components down to the laser emission beam size without strongly affecting the optical properties.
\end{abstract}

Keywords: Lasers and laser optics, Optical design and fabrication, Birefringence, Solderjet bumping, Low-stress soldering

\section{Background}

Laser manufacturers are nowadays driven by the wide variety of laser applications to build compact and robust devices that are able to perform in more stringent conditions [1]. To fulfill such demands, the common assembling techniques using clamping or adhesive means have to be substituted with more sophisticated approaches which enable components miniaturization (making them unsuitable for clamping methods), and more robust manufacturing that could offer a higher operational thermal range, vacuum compatibility or even the ability to withstand space radiation (making them unsuitable for

\footnotetext{
* Correspondence: pol.ribes@iof.fraunhofer.de

${ }^{1}$ Fraunhofer Institute for Applied Optics and Precision Engineering IOF, Albert-Einstein-Str. 7, 07745 Jena, Germany

${ }^{2}$ Institute of Applied Physics, Abbe Center of Photonics, Friedrich Schiller University Jena, Max-Wien-Platz 1, 07743 Jena, Germany
}

adhesive techniques) [2]. Techniques such as solderjet bumping can attune to the utilization of a minimized input of thermal energy, allowing for the assembly of brittle materials such as glasses, crystals or ceramics. This guarantees the possibility of components miniaturization while still assuring highly robust bond strength [3].

The solderjet bumping technique (Fig. 1), uses small spherical solder preforms of diameters in the range of 40 to $760 \mu \mathrm{m}$ made of various soft solder alloys (e.g. tinbased lead-free solders, low melting point indium alloys or high melting point eutectic gold-tin, gold-silicon or gold-germanium solders). The solder alloys are reflowed and jetted by a precise infrared laser pulse into the components to be bonded. However, in order to solder non-metallic materials, this process requires the prior application of wettable metallization layers onto the 


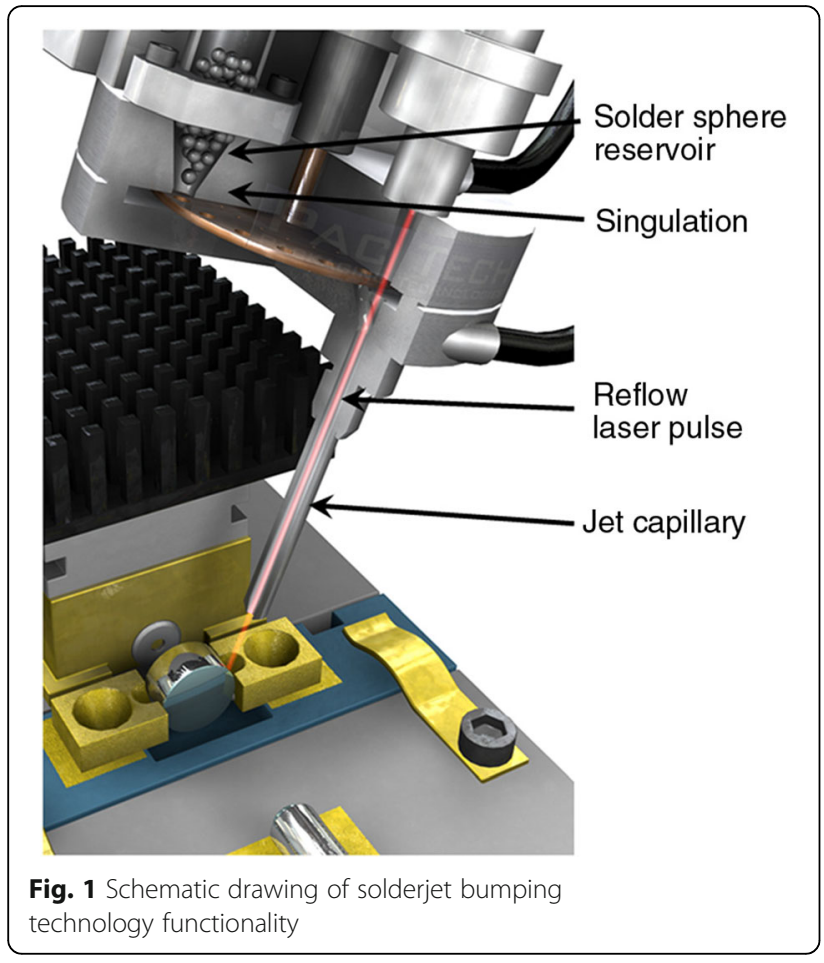

components to be bonded. The intermetallic layers could be applied, for instance, by physical vapor deposition [3].

The main disadvantage of replacing adhesives with soldering techniques is the inherent stress-induced birefringence in the optical components. For this reason, a study on the induced stress due to the packaging procedures has to be carried out. In a previous publication [4], a method was described by which to simulate and analyze the induced stresses from laser crystal packaging technologies, and it was shown that this solderjet bumping process can assemble small components down to $2 \mathrm{~mm}$ laser crystal cubes with only a residual stressinduced birefringence [4]. In the current publication, the technology limiting factors in terms of component sizes and soldering parametrization will be presented. We studied the propagation of laser beam emission through the soldered components, trying to discriminate the cases for which the induced stress created a beam depolarization ratio of more than $1 \%$.

\section{Methods}

In order to optimize the devices by miniaturizing the components while still guaranteeing enough robustness, a study with different components sizes and soldering approaches has been carried out. The study has been implemented with different cubes sizes made of fused silica (Table 1 and Fig. 2), which is a common and cheap material; used for example in output laser resonator mirrors.

\section{Stress simulation and measurement results}

We used ANSYS 17.0 to perform the analytical study of the soldering impact in the cases presented in Table 1. A transient thermal simulation using the alloy enthalpy for Sn96.5Ag3Cu0.5 (approximate melting temperature $21{ }^{\circ} \mathrm{C}$ ) was implemented to analyze the alloy solidification (thermal range from $230{ }^{\circ} \mathrm{C}$ to $22{ }^{\circ} \mathrm{C}$ ) onto the laser components [4]. Some examples of simulation models are shown in Fig. 2. The simulation results of the induced stress inside the soldered FS cubes along the laser beam path are presented in Fig. 3 .

We then assembled the simulated cases by soldering the real components (Fig. 4). The induced stress caused by the soldering upon the assembled components was finally measured using the Illis $\mathrm{GmbH}$ Polarimeter device and compared with the simulated results from ANSYS 17.0. The comparison study showed similar results in terms of stress magnitude and pattern distribution between the simulated and real induced stress on soldered samples as can be seen in Fig. 5 .

As an example, in Fig. 5 (b) one can see how solderjet bumping technology was used to assemble a $1 \mathrm{~mm}$ FS cube resulting in a stress that is non-measurable by a polarimeter device $(<0.1 \mathrm{MPa})$, due to the small amount of soldering alloy and reflow energy used. In addition, in the case of Fig. 5 (c) and (d), one can appreciate how the stress follows an analogous distribution pattern with similar values of measured and simulated stress, respectively. The stress measurement for components below $1 \mathrm{~mm}$ size was difficult to analyze due to the minimum size (millimeters range) and resolution $(0.1 \mathrm{MPa})$ of the polarimeter device. However, given that the results of the real-soldered cases with cube sizes of $2 \mathrm{~mm}$ and $1 \mathrm{~mm}$ are in agreement with the simulated measurements, we assume that results would be consistent in the case for smaller cube sizes.

\section{Stress post-processing and mathematical methodology} With a post processing analysis, we extracted from the ANSYS simulated results the vector principal stresses along the optical beam path (represented as a red beam in Fig. 6) inside the laser components, in order to study the component's birefringence and further lasing misbehavior. The ANSYS stress results were extracted in terms of inhomogeneities along the $\sigma_{k l}(z)$ (assuming a laser beam path along the middle of the component), and numerically approximated as a set of homogeneous layers [5] with different corresponding stress tensors $\sigma_{k l}^{(p)}$ as seen in Fig. 6 [4].

The mechanical induced stress onto the crystal has been analyzed following the produced changes on the crystal indicatrix (3D representation of crystal refractive indexes) $B_{i j}[6]$, 
Table 1 Different studied cases of fused silica (FS). Crystal cube sizes with variations of soldering bumps

\begin{tabular}{|c|c|c|c|c|}
\hline & & Crystal size & & \\
\hline & & $\begin{array}{l}\text { FS } 0.3 \mathrm{~mm} \\
\text { cube side }\end{array}$ & $\begin{array}{l}\text { FS } 1 \mathrm{~mm} \\
\text { cube side }\end{array}$ & $\begin{array}{l}\text { FS } 2 \mathrm{~mm} \\
\text { cube side }\end{array}$ \\
\hline $\begin{array}{l}\text { Soldering } \\
\text { preform size }\end{array}$ & $\begin{array}{l}300 \mu \mathrm{m} \\
\text { diameter }\end{array}$ & $\begin{array}{l}2 \text { bumps. } \\
1 \times \text { side }\end{array}$ & $\begin{array}{l}2 \text { bumps. } \\
1 \times \text { side }\end{array}$ & $\begin{array}{l}4 \text { bumps. } \\
2 \times \text { side }\end{array}$ \\
\hline & & & $\begin{array}{l}4 \text { bumps. } \\
2 \times \text { side }\end{array}$ & $\begin{array}{l}6 \text { bumps. } \\
3 \times \text { side }\end{array}$ \\
\hline & $\begin{array}{l}400 \mu \mathrm{m} \\
\text { diameter }\end{array}$ & $\begin{array}{l}2 \text { bumps. } \\
1 \times \text { side }\end{array}$ & $\begin{array}{l}2 \text { bumps. } \\
1 \times \text { side }\end{array}$ & $\begin{array}{l}2 \text { bumps. } \\
1 \times \text { side }\end{array}$ \\
\hline & & & $\begin{array}{l}4 \text { bumps. } \\
2 \times \text { side }\end{array}$ & $\begin{array}{l}4 \text { bumps. } \\
2 \times \text { side }\end{array}$ \\
\hline & & & & $\begin{array}{l}6 \text { bumps. } \\
3 \times \text { side }\end{array}$ \\
\hline & $\begin{array}{l}760 \mu \mathrm{m} \\
\text { diameter }\end{array}$ & $\begin{array}{l}2 \text { bumps. } \\
1 \times \text { side }\end{array}$ & $\begin{array}{l}2 \text { bumps. } \\
1 \times \text { side }\end{array}$ & $\begin{array}{l}2 \text { bumps. } \\
1 \times \text { side }\end{array}$ \\
\hline
\end{tabular}

$$
B_{i j}=B_{0, i j}+\Delta B_{i j}
$$

where the second-rank tensor $B_{0, i j}$ represents the freeof-stress indicatrix tensor, and $\Delta B_{i j}$ represents the indicatrix changes produced due to induced stress, which can also be expressed as [7],

$$
\Delta B_{i j}=\pi_{i j k l} \sigma_{k l}
$$

where the second-rank tensor $\sigma_{k l}$ represents the induced vector principal stress produced by the packaging extracted from ANSYS, and $\pi_{i j k l}$ is the fourth-rank piezooptic constants tensor described for each material [6]. With both Eqs. (1) and (2), we can calculate the indicatrix tensor $B_{i j}$ when certain stress $\sigma_{k l}$ is present. Then, the dielectric constant tensor $\epsilon_{i j}$ can be calculated using the following relation,

$$
\left[\epsilon_{\mathrm{ij}}\right]=\left[B_{i j}\right]^{-1}
$$

The resulting permeability matrix $\epsilon_{i j}$ is to be used for the subsequent optical simulation on the crystals by using VirtualLab Fusion software $[4,8]$.

\section{Results and discussion \\ Depolarization results and discussion}

In order to investigate the laser effects resulting from the stress-induced birefringence, the results extracted from ANSYS 17.0 were analyzed using VirtualLab Fusion software; several cases for the input wavelength per fused silica component condition were evaluated as seen in Table 2.

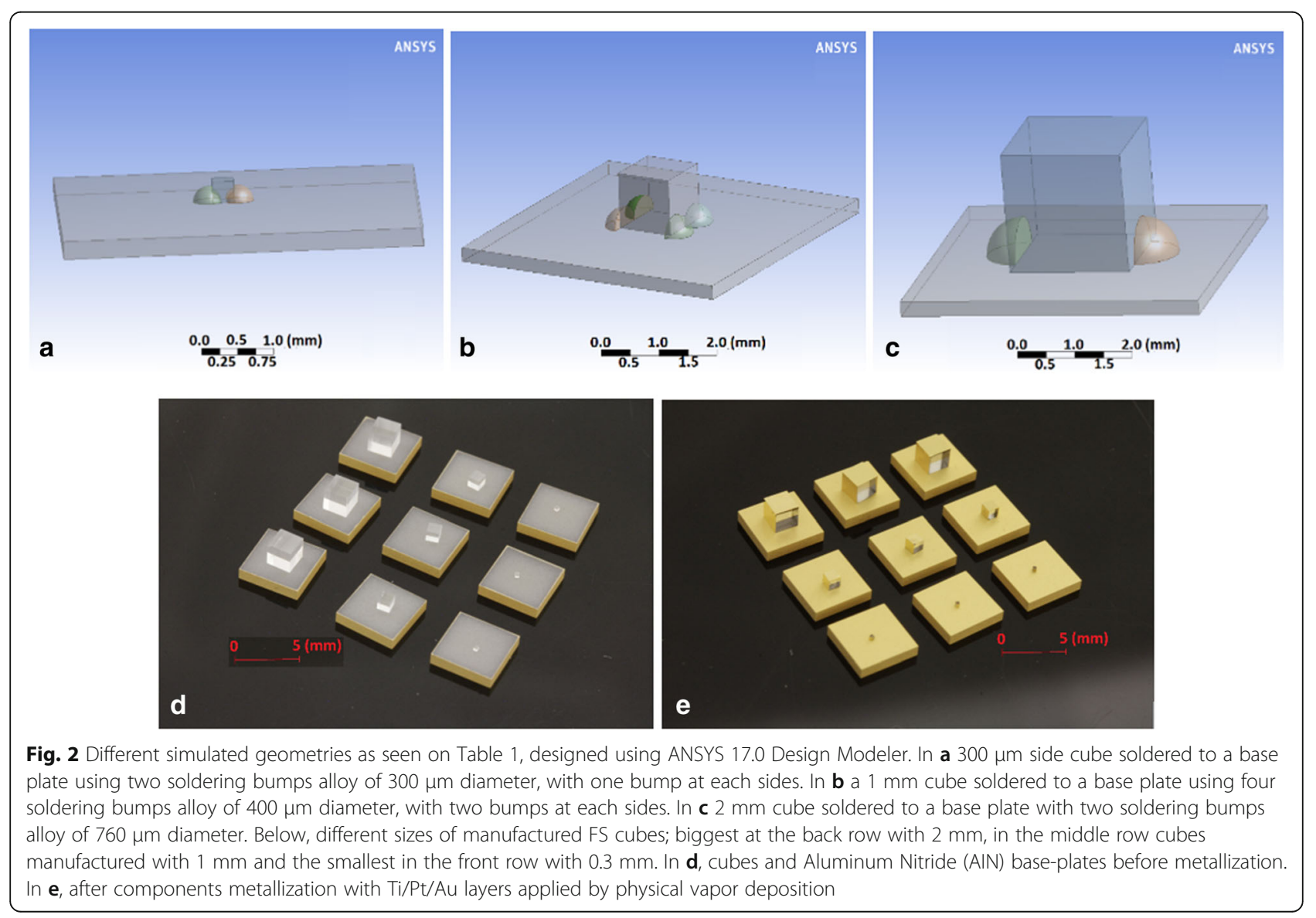




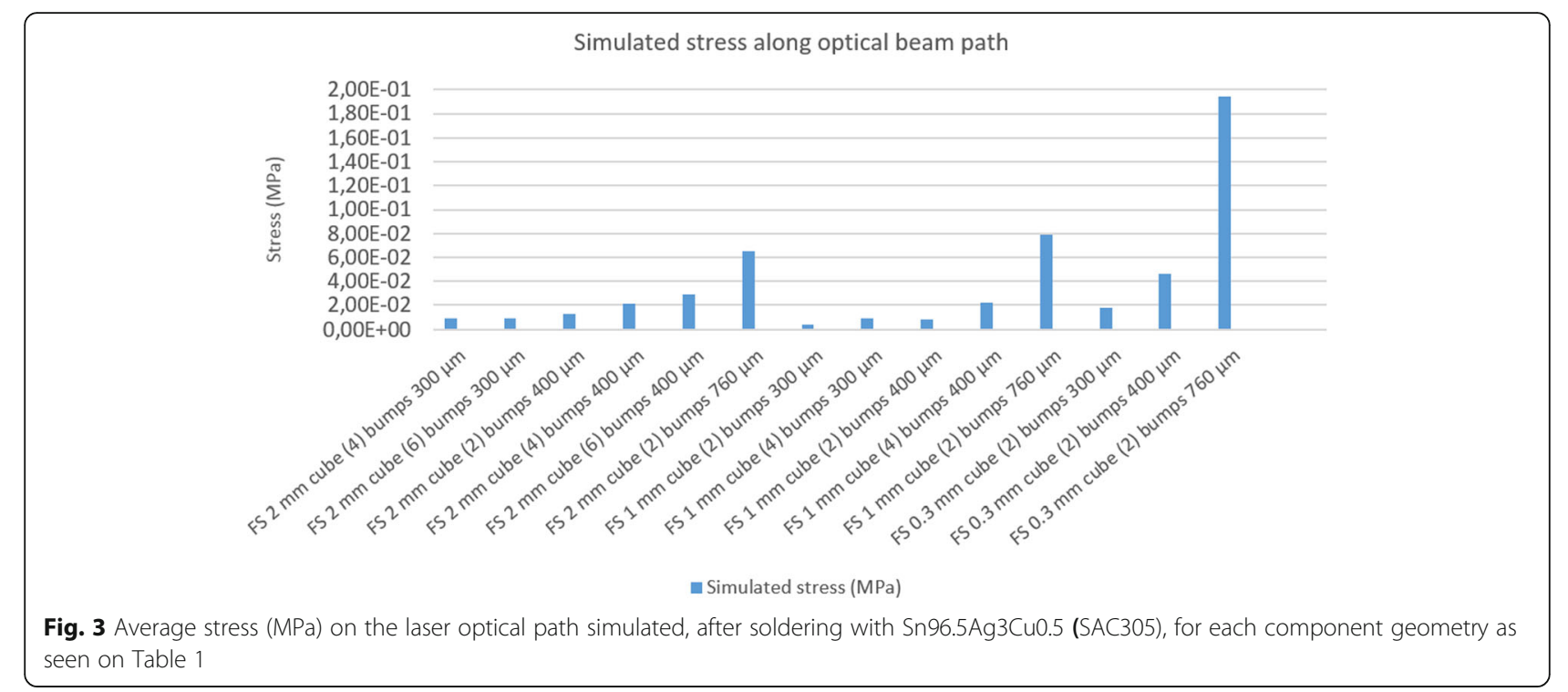

Introducing an input $\mathrm{E}_{\mathrm{y}}$-polarized Gaussian beam at $1064 \mathrm{~nm}$ (as it is a common wavelength for laser cavities with Nd:YAG crystals [9]), the output laser beam was studied in terms of laser depolarization. Taking into account one of the results with higher induced stress, as it is the $1 \mathrm{~mm}$ FS cube soldered with $760 \mu \mathrm{m}$ bumps, we obtained results for the beam depolarization ratio as seen on Fig. 7.

In Fig. 7 one can see a non-zero output field for the case without stress; this response is due to a crosstalk effect caused by reflection of light at the component surface. Comparing column cases (a) with no stress, and (b)-(c)\&(d) with applied stress, we see a beam mode change in the $\mathrm{E}_{\mathrm{x}}$-component; however this effect seems to introduce a maximum depolarization ratio below $0.001 \%$ for each one of the studied cases. On the other hand, our simulations were implemented with some simplifications applied, namely, using an unidimensional beam stress [4] along the middle of the laser beam path. This could be effective in cases for which the laser beam is much smaller than the beam cube size. In the cases for which the beam size is in the same order of magnitude as the laser component size, we have to ensure that we also take the stresses on the cube sides into account where more stress is present. In our study, and in order to avoid stress-effects produced on the sides of the $300 \mu \mathrm{m}$ cube where the beam is also present, we calculated the beam depolarization ratio for a maximum stress of approximately $0.5 \mathrm{MPa}$. In those cases, the beam depolarization ratio was about $0.01 \%$; and therefore insignificant for most laser applications. Similarly, the output beam profile did not change significantly from the initial Gaussian beam. The results for all the soldered and simulated cases, as described in Table 1, showed a small-induced stress effect produced by the solderjet bumping laser-crystal packaging technique.

\section{Bond strength results and discussion}

After assessing a low induced stress on the bonded components, the next step was to test if the various assembled cube sizes could withstand the high loads required, as are required in some laser applications [10]. For the analysis, we contrasted a theoretical bond strength calculated by accounting for the melted bump covered area for the different initial bumps sizes $(300 \mu \mathrm{m}, 400 \mu \mathrm{m}$ and $760 \mu \mathrm{m})$ by using alloy maximum yield strength (45 MPa for SAC305 [11]); and comparing it later with the real force required to tear apart the soldered

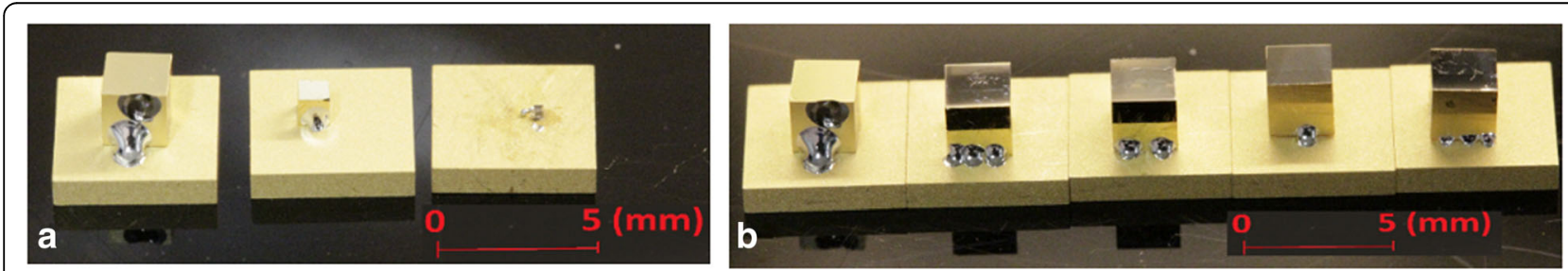

Fig. 4 Different sizes of manufactured and soldered FS cubes. In a, different soldered cube sizes ( $2 \mathrm{~mm}, 1 \mathrm{~mm}$ and $0.3 \mathrm{~mm}$ sides) soldered with different soldering alloy diameter sizes $(760 \mu \mathrm{m}, 400 \mu \mathrm{m}$ and $300 \mu \mathrm{m})$. In b, different $2 \mathrm{~mm}$ cubes soldered with different amount and size of soldering bumps 

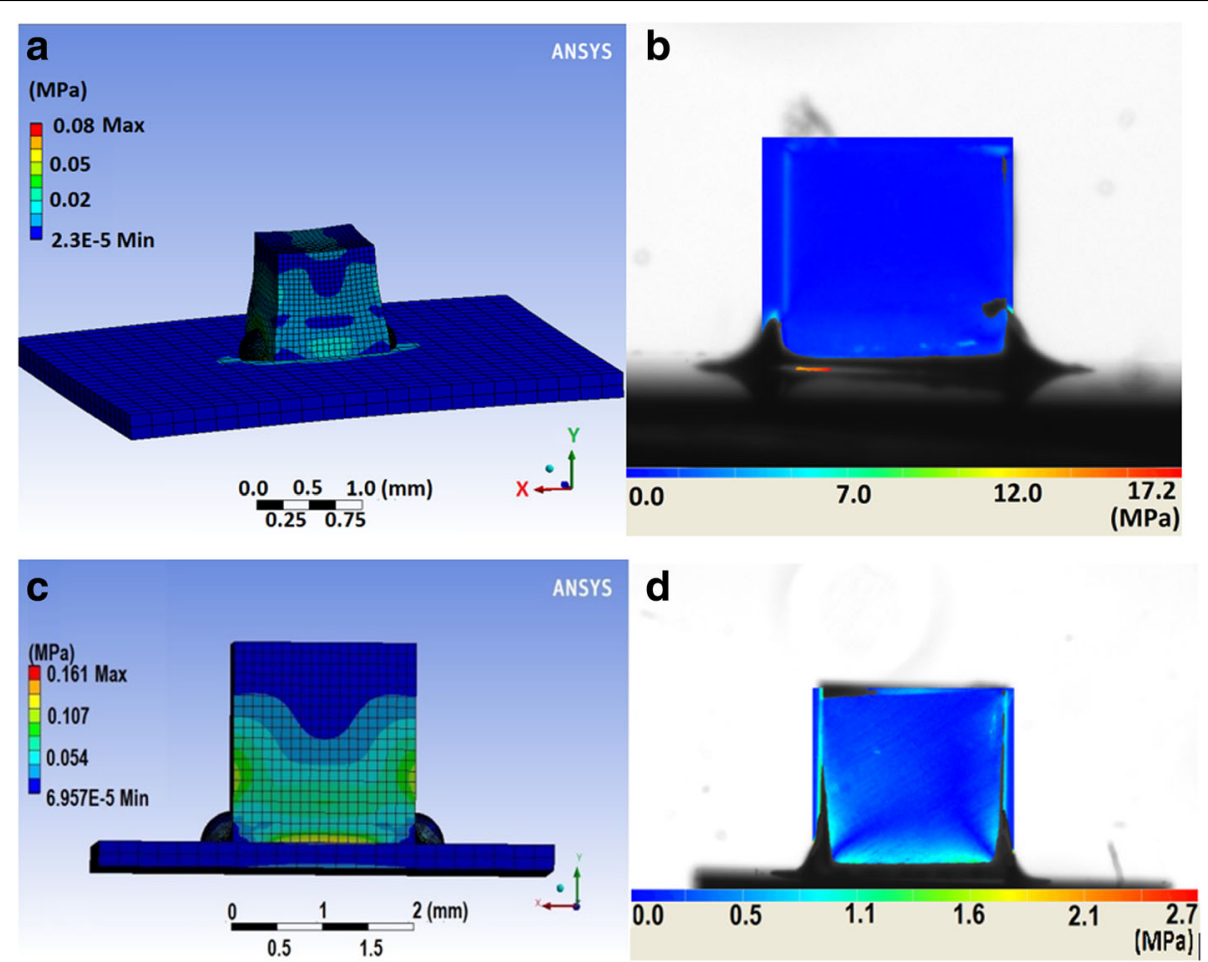

Fig. 5 In a minimum stress along laser beam path was obtained for the case of a $1 \mathrm{~mm}$ cube soldered with two 300 um solderjet bumps. In b, similar soldered case was measured with a polarimeter. The amount of induced stress was not measurable with the polarimeter in (b) since it was much lower than the limit of resolution and sensitivity of the polarimeter device $(<0.1 \mathrm{MPa})$. In $\mathbf{c}$ and $\mathbf{d}$ higher measurable stress on a $2 \mathrm{~mm}$ cube soldered with four $400 \mu \mathrm{m}$ bumps; both simulated and real-measured cases show similar stress distribution, with an amount of less than $1 \mathrm{MPa}$ induced stress close to the soldered areas

components. The push tests on soldered components were performed with a Zwick Roell GmbH Z020 (Fig. 8).

In the most of cases, the results show a similar trend between the expected theoretical force and the real join strength measured by performing the push test. For the cases in which the push test results differed from the theoretical expected strength (for example the $2 \mathrm{~mm}$ cube (4) bumps $300 \mu \mathrm{m}$ and the $1 \mathrm{~mm}$ cube (2) bumps $760 \mu \mathrm{m})$, the cause could be deviations in the final bump covered area or even defects on component edges that lead to component rupture though the FS glass.

These results, in contrast with the beam depolarization ratio analysis, could help users to select the component size and bond strength needed to manufacture miniaturized laser devices to be used in harsh environmental applications. The push test setup did not allow us to study the case of $300 \mu \mathrm{m}$ side cubes due to the small size of the components; however, as before, we can assume that

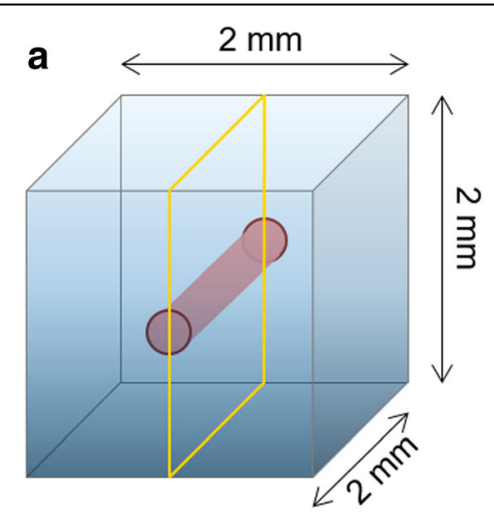

b

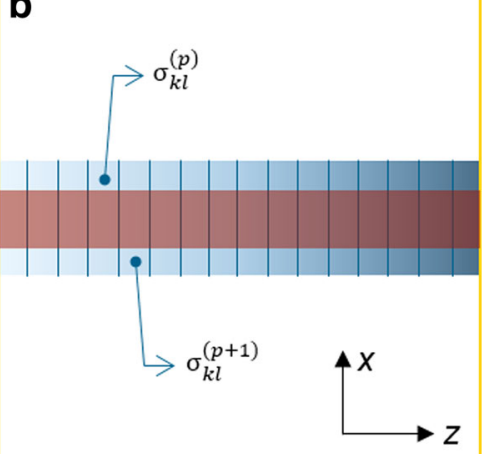

Fig. 6 In (a) example of 2 mm sided cube with the extracted set of homogeneous layers. In (b) homogeneous layers along the $z$-direction (laser beam path) expressed by the resulted stress in ANSYS $\boldsymbol{\sigma}_{k 1}^{(\mathbf{p})}$ 
Table 2 Studied laser produced beams and stress component conditions

\begin{tabular}{ll}
\hline Laser cavity beam & Component condition \\
\hline 1. Gaussian @1064 nm emission, & a. Ideal case: without stress \\
50 mm waist radius, Ey-polarization & b. Comparing case: with \\
& $(0.2 \times)$ stress by design \\
& c. Real case: with actual \\
applied stress \\
d. Comparing case: with \\
increased stress $(5 \times)$ by design
\end{tabular}

the results might be similar to the measured $1 \mathrm{~mm}$ and $2 \mathrm{~mm}$ cubes.

\section{Conclusions}

A simulation method as described in [4] has been followed, and the components soldering results have been contrasted with polarimeter stress measurements in order to investigate the optimization and miniaturization of laser components packaged with the solderjet bumping technique. The goal was to draw a distinction for cases at which the resulting beam depolarization reached values higher than $1 \%$. We found that the solderjet bumping technique showed much better results than the maximum expected results in all analyzed cases. In the study, we could simulate and solder components down to $300 \mu \mathrm{m}$ cube sizes, without strongly affecting the laser emission and with bonding strengths that comply with theoretical values. These results affirm solderjet bumping as a reliable technique that is able to assemble components down to the laser beam size (as in the case of fibers) without strongly affecting the laser beam polarization.

After establishing a trend between the expected and real strength of the assembled components in Fig. 8, and by also reporting higher differences on the $1 \mathrm{~mm}$ size cube results, the authors decided to perform a statistical analysis to understand these discrepancies. We performed a push test for forty samples of soldered FS cubes of $1 \mathrm{~mm}$ side. We divided the forty samples into two soldering parameter groups. The first, by soldering the cubes with four bumps of $400 \mu \mathrm{m}$ solder alloy, and the second group by soldering them with two bumps of $760 \mu \mathrm{m}$ SAC305 alloy. For the $1 \mathrm{~mm}$ FS cubes soldered with four bumps of $400 \mu \mathrm{m}$, the average force obtained from the push test was $5.40 \mathrm{~N}$, with a standard deviation of $3.65 \mathrm{~N}$. The average force for the $1 \mathrm{~mm}$ FS cubes soldered with two bumps of $760 \mu \mathrm{m}$ was $9.10 \mathrm{~N}$, with a standard deviation of $2.10 \mathrm{~N}$. Although these results are closer to the theoretical expected results, they still diverge from the calculated strength. The authors believe that the encountered differences for $1 \mathrm{~mm}$ cubes are a consequence of the manufactured $1 \mathrm{~mm}$ cubes' quality, which results in lower $\mathrm{Ti} / \mathrm{Pt} / \mathrm{Au}$ layers adhesion, ultimately compromising the component joint strength. The detailed results are submitted to the Smart System Integration 2018 Conference [12].

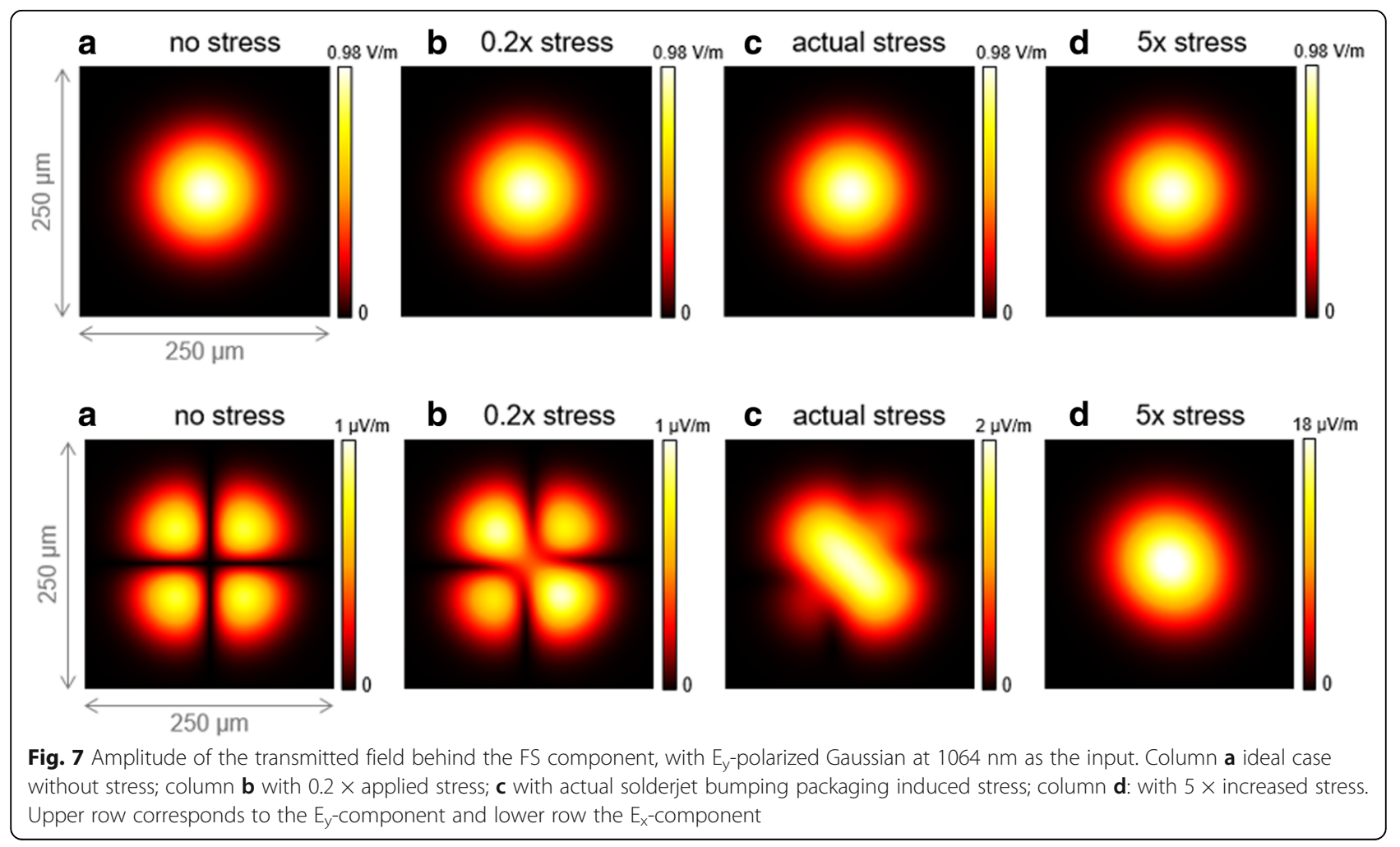




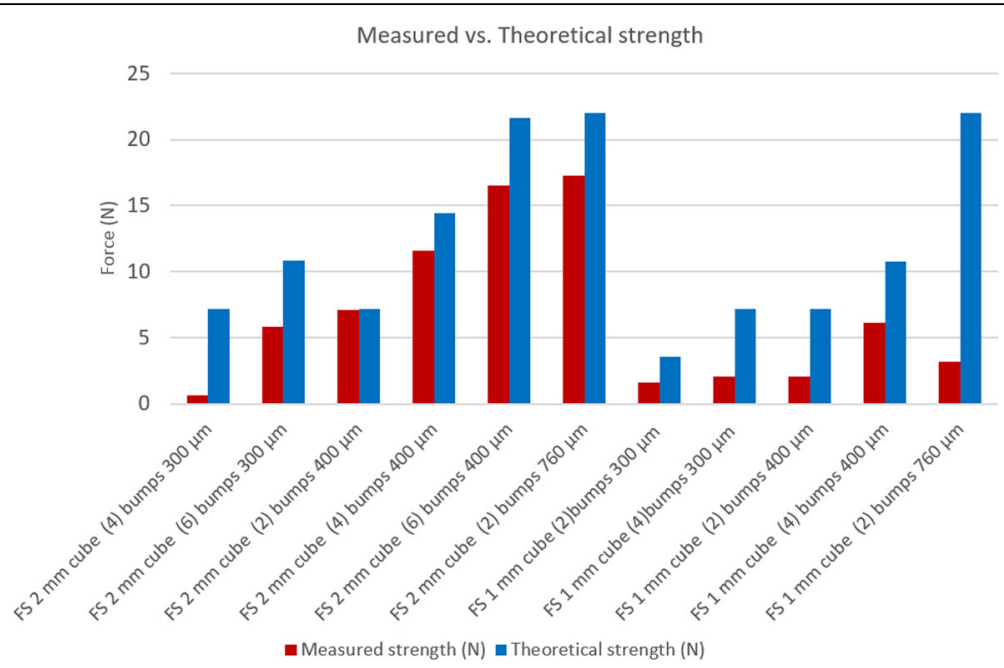

Fig. 8 The measurement of bonding strength between SAC305 alloy and fused silica cubes soldered on AIN baseplate using solderjet technique (red bars). This result follows similar trend with the theoretical bonding strength calculation (blue bars)

The study has been implemented with the use of FS material for the sake of simplicity. However, the method can be used for any other laser materials by adjusting the simulations using the corresponding material properties; easily found in [13].

Taking into account the mass of each of the FS cube sizes and considering, as an example, loads similar to the ones described for the Exomars ESA space mission $[10,14]$ (for which a manufactured robust laser is also required), each component would need to withstand a maximum of $0.3 \mathrm{~N}$ to comply with mission loads. However, as we have seen in Fig. 8, there are many cases that could handle a minimum force of $5 \mathrm{~N}$, greatly exceeding the mission demands. Thus, the solderjet bumping technique seems to be a reliable technique to assemble robust miniaturized laser devices without strongly affecting the emission in terms of beam quality and depolarization ratio.

Finally, the authors believe that the use of inorganic and flux-free metallic alloys provide components with better thermally conductive and radiation resistant joints (required for space applications), and more robust assemblies, when compared with formally state of the art technologies based on adhesive means [10].

\section{Abbreviations}

AIN: Aluminum Nitride; ESA: European Space Agency; FS: Fused Silica; SAC305: Sn96.5Ag3Cu0.5

\section{Acknowledgements}

(Not any)

\section{Funding}

Not applicable, all research was internally conducted.

\section{Availability of data and materials}

The datasets supporting the conclusions of this article are included within the article and its additional references.

\section{Authors' contributions}

PRP devised the miniaturization of laser components, stablished the tests to be performed and drafted the manuscript. BS carried out the soldering tests and the polarimeter analysis. SZ carried out the VirtualLab simulation analysis. EB supervised and coordinated the performed tests and the writing of the manuscript. FW developed the VirtualLab tools and supervised the components lasing behavior results. RE and AT followed the carried out research, provided ideas and guidelines as heads of the department and the institute; respectively. All authors read and approved the final manuscript.

\section{Authors' information}

Pol Ribes-Pleguezuelo: received his diploma degree in physics from the University of Barcelona, Spain in 2008. From 2010 to 2013, he worked as a researcher in design, manufacturing, and marketing of low/high power diodes and advanced solid-state lasers at Monocrom SL, Spain. Since 2013, he has been a PhD student at the Fraunhofer Institute of Applied Optics and Precision Engineering, Germany. His research interests include advanced solid-state lasers, optomechanical design/analyses and assembly technologies for space applications.

Brigitta Septriani: received her Bachelor of Science (Honours) degree in Physics from National University of Singapore in 2014. She is currently pursuing her Master's degree in Photonics at Abbe School of Photonics, Friedrich Schiller University in Jena. She previously worked as a Research Assistant in Quantum Optics Group in Centre for Quantum Technologies in Singapore.

Site Zhang: got his Master of Science degree in Photonics at the Abbe School of Photonics, Friedrich Schiller University Jena, in 2013. In the Applied Computational Optics Group, Institute of Applied Physics, he accomplished his Master thesis on spatio-temporal pulse shaping. Thenceforward he continued in this group as a PhD student. He has been concentrating on the modeling of light propagation in anisotropic media, e.g., crystal components for polarization manipulation.

Dr. Erik Beckert: received the diploma degree in precision mechanics and the Ph.D. degree in optoelectronics system integration from the Technical University IImenau, Germany, in 1997 and 2005, respectively. In 2001, he joined the Fraunhofer Institute for Applied Optics and Precision Engineering IOF, Jena, Germany. Since 2005, he is head of the micro-assembly and system integration group at Fraunhofer IOF. His research interests include i.e. assembly and integration of optical and opto-mechanical systems and soldering technology developments.

Dr. Ramona Eberhardt: received the diploma and Ph.D. degrees in chemistry from the Friedrich-Schiller-Universität Jena, Germany, in 1982 and 1987, respectively. From 1992 to 2004, she was group manager of the microassembly group at the Fraunhofer Institute for Applied Optics and Precision Engineering IOF, Jena. Since 2005, she is head of the Department of Precision Engineering at Fraunhofer IOF. Her experiences include precision fixation 
technologies like soldering and adhesive bonding, material sciences, and packaging of opto-mechanical systems.

Prof. Dr. Frank Wyrowski: was appointed Professor of Technical Physics at the Friedrich Schiller University of Jena, Germany, in 1996. He is the head of the Applied Computational Optics Group. In 1999, he founded the company LightTrans and in 2014 the company Wyrowski Photonics. In 2013, he received the grade of a Visiting Professor of the Chinese Academy of Science as well as of a Guest Professor at Harbin Institute of Technology (HIT). Prof. Dr. Andreas Tünnermann: received the diploma and Ph.D. degrees in physics from the University of Hannover, Germany, in 1988 and 1992, respectively. In 1997, he habilitated. He was head of the development department at the Laser Zentrum Hannover from 1992 to 1997. In 1998, he joined the Friedrich-Schiller-Universität Jena, Germany, as professor and director of the Institute of Applied Physics. In 2003, he additionally became director of the Fraunhofer Institute for Applied Optics and Precision Engineering IOF, Jena.

\section{Ethics approval and consent to participate}

Not applicable.

\section{Consent for publication}

Not applicable.

\section{Competing interests}

The authors declare that they have no competing interests.

\section{Publisher's Note}

Springer Nature remains neutral with regard to jurisdictional claims in published maps and institutional affiliations.

Received: 5 September 2017 Accepted: 30 October 2017

Published online: 06 November 2017

\section{References}

1. Ferrando, S., Galan, M., Mendez, E., Romeu, E., Montes, D., Isern, A., Jardi, M., Juliachs, J., Viera, G.: Innovative Optical Techniques Used in the Raman Instrument for Exomars. ICSO International Conference on Space Optics, Greece (2010)

2. Ribes, P., Koechlin, C., Burkhardt, T., Hornaff, M., Burkhardt, D., Kamm, A., Gramens, S., Beckert, E., Fiault, G., Eberhardt, R., Tünnermann, A.: Highprecision opto-mecanical lens system for space applications assembled by innovative local sodlering technique. Opt. Eng. 55(6), 065101 (2016). https:// doi.org/10.1117/1.OE.55.6.065101

3. Beckert, E., Oppert, T., Azdasht, G., Zakel, E., Burkhardt, T., Hornaff, M., Kamm, A., Scheidig, I., Eberhardt, R., Tünnermann, A., Buchmann, F.: Solder Jetting-A Versatile Packaging and Assembly Technology for Hybrid Photonics and Optoelectronical Systems, p. 406. Proceedings of IMAPS 42nd International Symposium on Microelectronics, California (2009)

4. Ribes-Pleguezuelo, P., Zhang, S., Beckert, E., Eberhardt, R., Wyrowski, F., Tünnermann, A.: Method to simulate and analyse induced stresses for laser crystal packaging technologies. Opt. Express. 25(6), 5927-5940 (2017). https://doi.org/10.1364/OE.25.005927

5. Bremmer, H.: The W.K.B approximation as the first term of a geometricoptical series. Commun. Pure Appl. Math. 4, 105-115 (1951)

6. Nye, J. F.: Physical properties of crystals, Oxford University Press, UK (2010)

7. Lü, Q., Wittrock, U., Dong, S.: Photoelastic effects in Nd:YAG rod and slab lasers. Opt. Laser Technol. 27(2), 95-101 (1995)

8. Zhang, S., Hellmann, C., Wyrowski, F.: Algorithm for the propagation of electromagnetic fields through etalons and crystals. Appl. Opt. 56, 4566-4576 (2017)

9. Encyclopedia of Laser Physics and Technology, https://www.rp-photonics. com/yag_lasers.html. Acessed 16 Aug 2017

10. Ribes-Pleguezuelo, P., Moral, A., Gilaberte, M., Rodríguez, P., Rodríguez, G., Laudisio, M., Galan, M., Hornaff, M., Beckert, E., Eberhardt, R., Tünnermann, A.: Assembly processes comparison for a miniaturized laser used for the exomars European Space Agency mission. Opt. Eng. 55(11), 116107 (2016). https://doi.org/10.1117/1.OE.55.11.116107

11. Mäusezahl, M., Hornaff, M., Burkhardt, T., Beckert, E.: Mechanical properties of laser-jetted SAC305 solder on coated optical surfaces. Phys. Procedia. 83 532-539 (2016)
12. Septriani, B., Ribes-Pleguezuelo, P., Beckert, E., Eberhardt, R., Tünnermann, A.: Bond Strength and Stability of Solderjet Bumping Packaging Technique for Laser Device Miniaturization. Subtited to the Smart System Integration Conference and Exhibition, Dresden (2017) in 5/10/2017

13. Martienssen, W., Warlimont H.: Springer Handbook of Condensed Matter and Materials Data Springer (2005)

14. Braghin, M., Exomars Project Team: ExoMars 2018 mission and system requirements document EXM-M2-RSD-ESA-00004 Issue 2, http://emits.sso. esa.int/emits-doc/ALENIA/Exomars/ExoMars_Mission_2018/EXM-M2-RSDESA-00004_Iss.2Rev1.pdf. Acessed 2 Nov 2017

\section{Submit your manuscript to a SpringerOpen ${ }^{\circ}$ journal and benefit from:}

- Convenient online submission

- Rigorous peer review

- Open access: articles freely available online

- High visibility within the field

- Retaining the copyright to your article

Submit your next manuscript at springeropen.com 